\title{
The Relationship Between Psychological Stress and Self-efficacy Among the Educational Supervisors in Karak
}

\author{
Huwaida Al-Tarawneh Prof. Ahmad Battah
}

\begin{abstract}
The present study aimed at exploring the relationship between psychological stress and self-efficacy among the educational supervisors in Karak, Jordan from their own perspective. To meet the study's goals, a questionnaire was developed. It consists from thirty items. The validity and reliability of the study's instrument were checked. The population consists from 120 educational supervisors in Karak, Jordan. The sample consists from all the members of the population. Those supervisors were selected purposively. Questionnaire forms were distributed to the sample members. 115 questionnaire forms only were retrieved. All of the retrieved forms are considered valid for statistical analysis. Thus, the response rate was $95.8 \%$. The researchers used several statistical methods. For instance, arithmetic means, standard deviations and the values of Pearson correlation coefficient were calculated. In addition, the values of Cronbach Alpha coefficient were calculated and the multiple analysis of variance (MANOVA) was conducted by the researchers. It was found that the respondents' psychological stress level is moderate. It was also found that the respondents' self-efficacy level is moderate. It was found that there is a statistically significant relationship -at the statistical significance level of a $\leq 0.05$ - between psychological stress and self-efficacy among the educational supervisors in Karak, Jordan. In the light of the aforementioned results, the researchers suggested several recommendations. For instance, the researchers recommend developing strategies by the Jordanian Ministry of Education for reducing the psychological stress levels of educational supervisors at Karak. That should be done because psychological stress can negatively affect the educational supervisors' work performance and capacity to do the required work tasks.
\end{abstract}

Keywords: Psychological Stress, Self-efficacy, Educational Supervisors

DOI: $10.7176 / \mathrm{JEP} / 11-6-13$

Publication date: February $29^{\text {th }} 2020$

\section{Introduction:}

Employees can significantly determine the success of an organization. However, they face problems that negatively affect their productivity and efficiency. Therefore, it is necessary to identify and address the problems that are faced by employees in organizations. Identifying and addressing the employees' problems shall enable organizations to meet their goals.

It should be noted that employees suffer from work-related stress and psychological stress. These types of stress can negatively affect their work performance. Therefore, it is necessary to explore these types of stress and identify their reasons. That shall enable organizations to reduce the work-related and psychological stress levels of employees. Reducing the latter levels shall enable employees to do the required tasks efficiently and improve their work performance.

Ahsan et al. (2009) suggest that some organizations seek meeting many requirements to achieve better results. He adds that adopting this approach shall increase the psychological stress level of employees. The increase of such level shall negatively affect the employees' work performance level. That is because suffering from psychological stress shall lead one to experience negative changes in his/her psychological state and thus, he/she shall be distracted when performing his/her work tasks.

Experiencing fatigue at work shall lead to increasing one's psychological stress level. Fatigue is usually experienced because one doesn't have the capabilities required for doing the required work tasks effectively. The psychological stress level serves as a significant indicator for one's well-being. That is because there is a strong relationship between psychological stress from one hand and mental and physical well-being from another hand (Shoji et al., 2015).

The researchers of the present study believe that one's professional life is one of his/her major concerns and may cause him/her much stress. That is because the organizational environment is usually highly competitive. It's also because one feels worried about the outcome of his/her work tasks. One experience this worriedness because such outcomes shall affect the way others treat him/her. Thus, worrying about professional life shall make one experience psychological stress. The latter stress shall negatively affect work performance level.

Al-Sa'dy (2012) adds that self-efficacy can significantly affect one's efficiency and performance at work. That is because there is a strong relationship between self-efficacy and psychological state. It is also because having a high self-efficacy level shall make one have faith in his capabilities and performance effectiveness. Thus, having a high self-efficacy level shall enable one to meet his/her goals (Al-Sa'dy, 2012).

Self-efficacy is a significant aspect of one's character. It determines one's behaviors in several social areas. In other words, one's perceptions for himself/herself shall determine his/her behaviors. Therefore, self-efficacy 
level shall affect one's efficiency in doing the tasks assigned to him/her (Ibrahim, 2016).

Al-Ali and Mohammad (2016) add that self-efficacy is considered one of the most important psychological determinants of behavior. That is because having a high self-efficacy level shall enable one to meet his/her personal goals. One's beliefs about his/her own capabilities and potentials shall enable him/her to have control over the surrounding environment. Thus, such beliefs shall affect one's capacity to do tasks (Al-Ali and Mohammad, 2016)

Educational supervision has been developing much. It is not restricted anymore to the inspection processes nor the detection of teachers' mistakes. In fact, educational supervision today aims to guide teachers and assist them. It aims at improving the educational process in all the school stages (Al-Ta'jan, 2016).

Educational supervision plays a significant role in improving the educational process. For instance, educational supervisors are considered the ones who are responsible the most for improving the teachers' performance and developing them professionally through providing them with support. They also play a significant role in improving and adjusting curricula. Thus, educational supervision is a significantly determinant of the effectiveness of the teaching process. Therefore, much attention should be provided to the educational supervision and the challenges facing educational supervisors. Strategies must be developed to address such challenges (AlShdaifat, 2014).

Based on the aforementioned information, it is necessary to identify the self-efficacy level of educational supervisors and the factors affecting this level. That should be done because self-efficacy can positively affect the educational supervisors' performance and efficiency. Therefore, the present study aimed to identify the relationship between psychological stress and self-efficacy among the educational supervisors in Karak.

\section{Statement of the Problem and the Study's Questions:}

Educational supervisors are responsible for performing many tasks and duties. For instance, they are responsible for developing teachers professionally and assisting them. They are responsible for promoting ethics among teachers and communicating and interacting socially with teachers. They must keep up with the latest changes and developments in the educational supervision field. Keeping up with such changes and developments shall positively affect their work performance level. All these responsibilities enforce many work-related burdens on educational supervisors. That shall make educational supervisors experience personal problems and work-related problems.

Psychological stress is experienced by many employees. That is because employees are required to meet many requirements which are not consistent with their mental or physical capabilities. Thus, that shall negatively affect their work performance (Vaezi and Fallah, 2011). Experiencing much psychological stress shall lead employees to experience fatigue at workplace. Thus, their efficiency at work shall be negatively affected. That shall negatively affect their job satisfaction level. Thus, experiencing much psychological stress is considered a serious problem that must be seriously addressed.

Many researchers suggest that self-efficacy is very important. That is because it affects one's behavior. It is because it affects one's capacity to do the required tasks (e.g. Al-Jahureye and Al-Thafry, 2018; Al-Ali and Mohammad, 2016; and Palmer et al., 2015). Therefore, the problem of the present study is represented in the following question: (What is the relationship between psychological stress and self-efficacy among the educational supervisors in Karak from their own perspective?)

The following sub-questions are derived from the above question:

Q.1 What is the psychological stress level of educational supervisors in Karak from their own perspective?

Q.2 What is the self-efficacy level of educational supervisors in Karak from their own perspective?

Q.3 Is there any statistically significant relationship -at the statistical significance level of a $\leq 0.05$ - between psychological stress and self-efficacy among educational supervisors in Karak?

Q.4 Is there any statistically significant difference -at the statistical significance level of a $\leq 0.05$ - between the respondents' psychological stress levels which can be attributed to their (gender, educational qualification, or experience)?

Q.5 Is there any statistically significant difference -at the statistical significance level of a $\leq 0.05$ - between the respondents' self-efficacy levels which can be attributed to their (gender, educational qualification, or experience)?

\section{The Study's Objectives:}

The present study aimed to

1. Identify the overall psychological stress level of the educational supervisors in Karak and their psychological stress levels about (their relationships with colleagues, their relationships with teachers, and financial issues)?

2. Identify the overall self-efficacy level of the educational supervisors in Karak and their behavioral selfefficacy, cognitive self-efficacy, and emotive self-efficacy levels

3. Identify the relationship between psychological stress and self-efficacy among the educational supervisors in Karak 
4. Identify whether there is any statistically significant difference -at the statistical significance level of a $\leq 0.05$ - between the respondents' psychological stress levels which can be attributed to their (gender, educational qualification, or experience)

5. Identify whether there is any statistically significant difference -at the statistical significance level of a $\leq 0.05$ - between the respondents' self-efficacy levels which can be attributed to their (gender, educational qualification, or experience)

\section{The Study's Significance:}

The present study is significant on the theoretical and practical levels:

\subsection{The theoretical significance:}

The present study is significant because:

- It identifies the psychological stress level of the educational supervisors in Karak and its relationship with their self-efficacy level. That shall enrich the relevant theoretical knowledge

- It shall enrich the relevant literature that address psychological stress and self-efficacy.

- There are only few studies that shed a light on the relationship between psychological stress and selfefficacy among the educational supervisors in Karak

\subsection{The practical significance:}

The present study is significant because

- The results of the present study shall benefit the managers and the decision makers working at educational institutions. They shall enable those managers and decision makers to improve their work performance

- It targets an important category of people (i.e. educational supervisors). For instance, educational supervisors can significantly affect the quality of the provided education. They can improve such quality through assisting teachers, and adjusting curricula

- It shall enable decision makers to develop effective strategies for reducing the psychological stress level of educational supervisors and fighting against the consequences of such stress

- It shall promote awareness among the officials working at the Jordanian Ministry of Education about the significance of taking measures for reducing the psychological stress of educational supervisors in Karak.

\section{The theoretical framework:}

Employees in organizations suffer from much stress, including psychological stress. That negatively affects their performance and efficiency levels at work. It negatively affects their relationships with others. Due to the seriousness of psychological stress, it is necessary to identify its causes, consequences and methods of addressing it.

\subsection{Psychological stress}

The psychological stress level is an indicator for the anxiety level that one suffers from. It is affected by external and internal factors. It affects one's behavior. It affects one's personal balance level (Abdullah, 2004). It level is an indicator for the amount of burdens enforced on one. Burdens have negative social and psychological effects. Psychological stress may manifest through psychological symptoms, such as: sadness, depression, and anxiety. It may manifest through physical symptoms. It may make one experience a state of psychological imbalance. It negatively affects one's capacity to do the required tasks (Al-Khaldy, 2008).

Welkenson (2013) adds that experiencing a little psychological stress is useful because it shall motivate one to make achievements and utilize his/her potentials. Therefore, it is important to experience a little psychological stress in life (Welkenson, 2013). However, experiencing much psychological stress in an ongoing manner shall lead to experiencing much anxiety. That shall lead to experiencing hormonal imbalance. Such imbalance shall make one suffer from many illnesses. It should be noted that psychological stress serves as a coping mechanism with stressful situations (Krohne, 2002).

Al-Gareer and Abu Sa'd (2009) add that internal and external pressures make one experience psychological stress. Internal pressures are related to one's perceptions about himself/herself, whereas external pressures are related to life events (Al-Gareer and Abu Sa'd, 2009). The researchers of the present study add that psychological stress refers to the feelings experienced in stressful situations at social life or workplace. They believe that psychological stress may manifest through psychological symptoms, such as: anxiety, sadness and fear. They believe that psychological stress shall negatively affect one's future and make one worried about the outcomes of his/her work. They believe that psychological stress shall negatively affect one's performance.

\subsection{Self-efficacy}

Self-efficacy refers to one's expectations and judgments about his/her own performance and behaviors. Such 
expectations and judgments shall affect one's work performance. Self-efficacy refers to one's faith in his capacity to do tasks efficiently (Artino, 2006).

Self-efficacy is an indicator for one's capacity to control his/her own behaviors in accordance with his/her personal judgments and beliefs. It is an indicator for one's capacity to control his/her own emotions and ideas. It should be noted that one's beliefs shall directly affect his/her own behaviors and acts (Al-Olwan and Al-Mahasneh, 2011).

Alawneh et al. (2006) add that self-efficacy refers to one's beliefs about his/her own capacity to meet the required goals and develop plans efficiently. They add that self- efficacy refers to one's beliefs about his/her own capacity to do the required tasks effectively in the light of the changing circumstances.

Talafha and Al-Hemran (2013) add that self-efficacy refers to one's assumptions about his/her own capacity to learn in various situations. They add that self-efficacy refers to one's belief about his/her own capacity to meet the required requirements. They add that self-efficacy refers to one's belief about his/her own capacity to learn information that enables him/her to overcome problems and improve performance (Talafha and Al-Hemran, 2013).

The researchers of the present study suggest that self-efficacy refers to one's capacity to control his/her own potentials and capabilities in order to do the required tasks. They add that self-efficacy refers to one's capacity to control his/her behaviors to achieve the required performance. They add that having a high self-efficacy level shall enable one to utilize his/her potentials to the maximum possible level.

\section{Previous Studies:}

Coffman and Gilligan (2002) aimed to explore the relationship between social support, stress, and self-efficacy from one hand and life satisfaction from another hand among students. They selected a sample consisting from 94 first-year college students. Students who show higher levels of social support and self-efficacy and lower levels of perceived stress also reported higher levels of life satisfaction. It was found that $41 \%$ of the changes in life satisfaction are attributed to stress and social support.

Totolo (2011) aimed to identify the attitudes of school supervisors towards using computer technology for doing their administrative tasks in Botswana secondary schools. The sample consists from eleven (11) school supervisors who were working at Botswana. The latter researchers used a questionnaire for collecting data. It was found that respondents have positive attitudes towards using computer technology for doing their administrative tasks. It was found that most of the administrative tasks that the respondents do include: receiving, storing and processing data. It was found that that respondents do not receive adequate training.

Abu Rahmeh (2012) aimed to identify the work-related stress and job satisfaction levels of educational supervisors. The sample consists from 189 educational supervisors. The latter researcher used a questionnaire for collecting data. It was found that respondents' work-related stress is moderate. It was found that there isn't any statistically significant difference between the respondents' work-related stress levels which can be attributed to gender or school type. It was found that respondents' job satisfaction level is moderate.

Al-Shdaifat (2014) aimed to explore the role of educational supervisors in improving the professional performance of social studies teachers in the schools affiliated with the directorates of the Northwestern Badiah in Mafraq. The sample consists from 99 female and male teachers. The latter researcher used a questionnaire for collecting data. It was found that educational supervisors play a moderate role in improving the professional performance of the social studies teachers in schools affiliated with the directorates of the Northwestern Badiah in Mafraq. The assessment area was ranked first, whereas the planning area was ranked last.

Al-Shawa (2016) aimed to identify the self-efficacy level of the officers working at the Palestinian security institutions. He aimed to explore the relationship between psychological stress and self-efficacy among these officers. A correlative descriptive approach was adopted. The latter researcher used a questionnaire for collecting data. Questionnaire forms were distributed to 288 officers. It was found that the respondents' psychological stress level is high. It was found that the respondents' psychological stress level is low. It was found that there is a statistically significant relationship -at the statistical significance level of a $\leq 0.05$ - between psychological stress and self-efficacy among the respondents.

Al-Ta'jan (2016) aimed to explore and assess the competencies of educational supervisors in Jordan. The sample consists from 32 female and male educational supervisors. The latter researcher used a questionnaire for collecting data. Several results were concluded by the latter researcher. For instance, he found that the extent of possessing technical competencies by the respondents is high. It was found that technical competencies are ranked first, whereas the professional competencies are ranked last. It was found that there are differences between the respondents' extent of possessing competencies which can be attributed to their gender and educational qualifications.

Arslan (2017) aimed to explore the relationship between educational stress and emotional self-efficacy. 232 secondary school students were sampled. The convenience sampling method was used. A questionnaire was used for collecting data. It was found that there is a significant relationship educational stress and emotional self-efficacy. It was found that the higher the self-efficacy level, the lower the educational stress shall be. 
Al-Fakhouri (2018) aimed to identify the psychological stress level of the teachers of blind students in the Northern cities of Palestine. She aimed to identify the relationship between psychological stress and perceived self-efficacy among those teachers. A correlative descriptive approach was adopted. The sample consists from 56 female and male teachers. A psychological stress scale and a perceived self-efficacy scale were used. It was found that the respondents' psychological stress level is moderate and the respondents' perceived self-efficacy level is moderate. It was found that there is a statistically significant relationship between the psychological stress and the perceived self-efficacy among respondents.

\section{The Study's Approach:}

A correlative descriptive approach was adopted. Data was collected through reviewing the relevant literature and using a questionnaire. This approach is adopted by many researchers for offering readers a sensory description for things and items. It can be adopted for identifying whether certain sensory attributes are deemed accepted or not. It may be adopted by researchers to explore variables and their dimensions and constituents (Lawless and Heymann, 1999).

\section{The Study's Population and Sample:}

The study's population is represented in all the educational supervisors working at Karak, Jordan. To be specific, it consists from 120 educational supervisors; 80 male educational supervisors and 40 female educational supervisors. These numbers are obtained from the statistics report of the personnel affair department of Karak directorate of education, 2018). A purposive sample was selected. It is represented in all the members of the study's population. Questionnaire forms were distributed to all the sample members. However, 115 questionnaire forms only were retrieved. All of the retrieved forms are considered valid for statistical analysis. Thus, the response rate was $95.8 \%$. It is an accepted rate and enables the researchers to meet the study's goals.

\section{The Study's Instruments:}

To meet the study's goals, a questionnaire was developed and the five point Likert scale was adopted. The latter scale consists from five categories; strongly agree, agree, moderate, disagree, and strongly disagree. These categories represent the following scores respectively: 5, 4, 3,2 and 1. The questionnaire consists from three parts. The first part aims to collect demographic data. The second part aims to measure the overall psychological stress level and its sub-variables. It was developed based on the studies of Al-Shawa (2016) and Al-Fakhouri (2018). The third part aims to measure the overall self-efficacy level and its sub-variables. It was developed based on the studies of Al-Yousif (2013), Shawa (2016) and Al-Fakhouri (2018).

To measure the validity of the instrument, the researchers measured the content validity. That was done through passing the questionnaire to several experts who possess much experience and knowledge to provide their views. Those experts are eight (8) university professors and head of departments who work at Jordanian universities. They recommended keeping all the items of the questionnaire. However, they recommended rewriting some statements.

To measure the reliability of the instrument, the researchers calculated the values of the internal consistency coefficient. That was done through calculating the values of Cronbach Alpha coefficient. It was calculated after distributing the questionnaire forms to an exploratory sample that consists from 10 educational supervisors. The values of Cronbach Alpha coefficient of the psychological stress scale are within the range of $0.76-0.82$. The values of Cronbach Alpha coefficient of the self-efficacy scale are within the range of 0.75- 0.80. These values are considered accepted and enable the researchers to meet the study's goals.

\section{Criteria for classifying means:}

To set criteria for classifying means, the following equation was used:

The gap between each two criteria $=($ The maximum value - the minimum value $) /$ the number of required criteria Thus, the gap between each two criteria $=(5-1) / 3=1.33$

The latter value (1.33) was added to each value to set the three classification criteria listed below:

Low: 1 - Less than 2.33

Moderate: 2.33 - Less than 3.66

High: More than 3.66-5

\section{Results}

11.1 Results related to the first question:

Q.1 What is the psychological stress level of educational supervisors in Karak from their own perspective?)

To answer this question, arithmetic means and standard deviations were calculated for the psychological stress variables jointly and separately. Table (1) presents these values below 
Table (1): The arithmetic means and standard deviations for the psychological stress level of educational supervisors in Karak

\begin{tabular}{|l|l|l|l|l|}
\hline Rank & Dimension & Arithmetic mean & Standard deviation & Degree \\
\hline 1 & Financial issues & 3.44 & .54 & Moderate \\
\hline 2 & Relationships with teachers & 3.36 & .54 & Moderate \\
\hline 3 & Relationships with colleagues & 3.29 & .51 & Moderate \\
\hline & Total & 3.36 & .44 & Moderate \\
\hline
\end{tabular}

Based on table (1), it was found that the overall psychological stress level of educational supervisors in Karak is moderate. That is because the total mean is 3.36. The standard deviation is 0.44 . It was found that the psychological stress level of respondents about financial issues is moderate because the relevant mean is 3.44 . It was found that the psychological stress level of respondents about their relationships with teachers is moderate because the relevant mean is 3.36. It was found that the psychological stress level of respondents about their relationships with colleagues is moderate because the relevant mean is 3.29. Psychological stress about financial issues is ranked first. Psychological stress about relationships with teachers is ranked second. Psychological stress about relationships with teachers is ranked third.

\subsection{Results related to the second question:}

Q.2 What is the self-efficacy level of educational supervisors in Karak from their own perspective?

To answer this question, arithmetic means and standard deviations were calculated for the self-efficacy variables jointly and separately. Table (1) presents these values below

Table (2): The arithmetic means and standard deviations for the self-efficacy level of educational supervisors in Karak.

\begin{tabular}{|l|l|l|l|l|}
\hline Rank & Dimension & Arithmetic mean & Standard deviation & Degree \\
\hline 1 & Behavioral self-efficacy & 3.48 & .48 & Moderate \\
\hline 2 & Cognitive self-efficacy & 3.41 & .46 & Moderate \\
\hline 3 & Emotive self-efficacy & 3.38 & .53 & Moderate \\
\hline & Total & 3.42 & .41 & Moderate \\
\hline
\end{tabular}

Based on table (2), it was found that that the overall self-efficacy level of educational supervisors in Karak is moderate because the relevant mean is moderate. That is because the total mean is 3.42 . The total standard deviation is 0.41 . It was found that the respondents' behavioral self-efficacy level is moderate because the relevant mean is 3.48. It was found that the respondents' cognitive self-efficacy level is moderate because the relevant mean is 3.41. It was found that the respondents' emotive self-efficacy level is moderate because the relevant mean is 3.38. Behavioral self-efficacy is ranked first, whereas the cognitive self-efficacy is ranked second. The emotive self-efficacy is ranked third.

\subsection{Results related to the third question}

Q.3 Is there any statistically significant relationship -at the statistical significance level of a $\leq 0.05$ - between psychological stress and self-efficacy among educational supervisors in Karak?

To answer this question, the researchers calculated the values of Pearson correlation coefficient to explore the relationships between the psychological stress variables and the self-efficacy variables jointly and separately. Table (3) presents these values below:

Table (3): The values of Pearson correlation coefficient for identifying the relationship between the psychological stress variables and the self-efficacy variables jointly and separately

\begin{tabular}{|c|c|c|c|c|c|c|c|c|}
\hline & \multicolumn{8}{|c|}{ The dependent variables } \\
\hline & $\begin{array}{l}\text { Behavioral } \\
\text { efficacy }\end{array}$ & self- & $\begin{array}{l}\text { Cognitive } \\
\text { efficacy }\end{array}$ & self- & $\begin{array}{l}\text { Emotive } \\
\text { efficacy }\end{array}$ & self- & Total & \\
\hline $\begin{array}{l}\text { The } \\
\text { independent } \\
\text { variables }\end{array}$ & $\begin{array}{l}\text { Pearson } \\
\text { correlation } \\
\text { coefficient } \\
\end{array}$ & Sig. & $\begin{array}{l}\text { Pearson } \\
\text { correlation } \\
\text { coefficient }\end{array}$ & Sig. & $\begin{array}{l}\text { Pearson } \\
\text { correlation } \\
\text { coefficient } \\
\end{array}$ & Sig. & $\begin{array}{l}\text { Pearson } \\
\text { correlation } \\
\text { coefficient }\end{array}$ & Sig. \\
\hline $\begin{array}{l}\text { Relationships } \\
\text { with colleagues }\end{array}$ & $.497 *$ & .000 & $.578^{*}$ & .000 & $.372 *$ & .000 & $.575^{*}$ & .000 \\
\hline $\begin{array}{l}\text { Relationships } \\
\text { with teachers }\end{array}$ & $.446^{*}$ & .000 & $.631^{*}$ & .000 & $.494^{*}$ & .000 & $.628 *$ & .000 \\
\hline Financial issues & $.652 *$ & .000 & $.565^{*}$ & .000 & $.570^{*}$ & .000 & $.717^{*}$ & .000 \\
\hline Total & $.640 *$ & .000 & $.716^{*}$ & .000 & $.577 *$ & .000 & $.772 *$ & .000 \\
\hline
\end{tabular}

*The statistical significance level is a $\leq 0.05$

Based on table (3), it was found that there are statistically significant relationships between the psychological 
stress variables and the self-efficacy variables jointly and separately. Thus, there is a statistically significant relationship -at the statistical significance level is a $\leq 0.05$ - between psychological stress and self-efficacy among the educational supervisors in Karak. That is because the total value is .772.

It was found that psychological stress about financial issues has the strongest relationship with the selfefficacy dimensions jointly because the total value is 0.717 . It was found that psychological stress about relationships with colleagues has the weakest relationship with the self-efficacy dimensions jointly because the total value is 0.575 .

\subsection{Results related to the fourth question}

Q.4 Is there any statistically significant difference -at the statistical significance level of a $\leq 0.05$ - between the respondents' psychological stress levels which can be attributed to their (gender, educational qualification or experience)?

To answer this question, arithmetic means and standard deviations of psychological stress levels were calculated in accordance with the respondents' gender, educational qualification, or experience. Table (4) presents these values below.

Table (4): Arithmetic means and standard deviations of psychological stress levels in accordance with the respondents' gender, educational qualification or, experience.

\begin{tabular}{|l|l|l|l|l|}
\hline Variable & \multicolumn{1}{|c|}{ Category } & Frequency & Arithmetic mean & Standard deviation \\
\hline \multirow{3}{*}{ Gender } & Male & 75 & 3.31 & .43 \\
\cline { 2 - 5 } & Female & 40 & 3.45 & .45 \\
\hline \multirow{5}{*}{ Educational qualification } & BA degree & 18 & 3.31 & .49 \\
\cline { 2 - 5 } & MA degree & 72 & 3.39 & .42 \\
\cline { 2 - 5 } & PhD degree & 25 & 3.33 & .46 \\
\hline \multirow{5}{*}{ Experience } & Less than 5 years & 22 & 3.30 & .34 \\
\cline { 2 - 5 } & 5 years - less than 10 years & 53 & 3.41 & .48 \\
\cline { 2 - 5 } & 10 years or more & 40 & 3.34 & .42 \\
\hline
\end{tabular}

It appears that there are differences between the means presented in table (4). To identify whether these differences are statistically significant, the multiple analysis of variance (MANOVA) was conducted. Table (5) below presents the results of the latter analysis.

Table (5): The results of the multiple analysis of variance (MANOVA)

\begin{tabular}{|l|l|l|l|l|l|}
\hline Source of variance & Sum of squares & Degree of freedom & Mean squares & F value & Sig. \\
\hline Educational qualification & .368 & 2 & .184 & .972 & .382 \\
\hline Gender & .493 & 1 & .493 & 2.598 & .110 \\
\hline Experience & .199 & 2 & .099 & .525 & .593 \\
\hline Error & 18.767 & 99 & .190 & & \\
\hline Total & 1326.413 & 115 & & & \\
\hline
\end{tabular}

*The statistical significance level is a $\leq 0.05$

Based on table (5), it was found that there isn't any statistically significant difference -at the statistical significance level of a $\leq 0.05$ - between the respondents' psychological stress levels that can be attributed to their (gender, educational qualification, or experience).

\subsection{Results related to the fifth question}

Q.5 Is there any statistically significant difference -at the statistical significance level of a $\leq 0.05$ - between the respondents' self-efficacy levels which can be attributed to their (gender, educational qualification, or experience)? To answer this question, arithmetic means and standard deviations of self-efficacy levels were calculated in accordance with the respondents' gender, educational qualification or experience. Table (6) presents these values below.

Table (6): Arithmetic means and standard deviations of self-efficacy levels in accordance with the respondents' gender, educational qualification or experience

\begin{tabular}{|l|l|l|l|l|}
\hline Variable & Category & Frequency & Arithmetic mean & Standard deviation \\
\hline \multirow{2}{*}{ Gender } & Male & 75 & 3.38 & .42 \\
\cline { 2 - 5 } & Female & 40 & 3.50 & .38 \\
\hline \multirow{2}{*}{$\begin{array}{l}\text { Educational } \\
\text { qualification }\end{array}$} & BA degree & 18 & 3.37 & .48 \\
\cline { 2 - 5 } & MA degree & 72 & 3.45 & .35 \\
\cline { 2 - 5 } & PhD degree & 25 & 3.38 & .50 \\
\hline \multirow{2}{*}{ Experience } & Less than 5 years & 22 & 3.49 & .32 \\
\cline { 2 - 5 } & 5 years - less than 10 years & 53 & 3.40 & .47 \\
\cline { 2 - 5 } & 10 years or more & 40 & 3.42 & .37 \\
\hline
\end{tabular}


It appears that there are differences between the means presented in table (6). To identify whether these differences are statistically significant, the multiple analysis of variance (MANOVA) was conducted. Table (7) below presents the results of the latter analysis.

Table (7): The results of the multiple analysis of variance (MANOVA)

\begin{tabular}{|l|l|l|l|l|l|}
\hline Source of variance & Sum of squares & Degree of freedom & Mean squares & F value & Sig. \\
\hline Educational qualification & .049 & 2 & .024 & .138 & .871 \\
\hline Gender & .223 & 1 & .223 & 1.271 & .262 \\
\hline Experience & .183 & 2 & .091 & .520 & .596 \\
\hline Error & 17.375 & 99 & .176 & & \\
\hline Total & 1371.076 & 115 & & & \\
\hline
\end{tabular}

*The statistical significance level is a $\leq 0.05$

Based on table (7), it was found that there isn't any statistically significant difference -at the statistical significance level of a $\leq 0.05$ - between the respondents' self-efficacy levels which can be attributed to their gender, educational qualification or experience

\section{Discussion:}

12.1Discussion related to the first question:

Q.1 What is the psychological stress level of educational supervisors in Karak from their own perspective?)

It was found that the overall psychological stress level of educational supervisors in Karak is moderate. That is because the total mean is 3.36. Psychological stress about financial issues is ranked first. Psychological stress about relationships with teachers was ranked second. Psychological stress about relationships with teachers is ranked third.

Educational supervisors in Karak experience psychological stress because they face many challenges and problems at work. It is also because they don't receive the income they ought to receive. In other words, it is because they face financial pressures. It is also because educational supervisors don't deal professionally with teachers. It is because schools in Karak adopt rigid management methods which negatively affect the educational supervisors' relationships with each other. That shall make educational supervisors compete much with one another. Thus, their anxiety and fear levels shall increase leading to raising the psychological stress levels.

Educational supervisors in Karak experience psychological stress because they can't separate their personal problems from their work-related problems. That shall make the workplace environment turbulent and inconvenient for working.

The latter result is consistent with the result concluded by Al-Fakhouri (2018). The latter researcher found that the respondents' psychological stress level is moderate. However, the latter result is inconsistent with the result concluded by Al-Shawa (2016). The latter researcher found that the respondents' psychological stress level is high.

\subsection{Discussion related to the second question:}

Q.2 What is the self-efficacy level of educational supervisors in Karak from their own perspective?)

It was found that that the overall self-efficacy level of educational supervisors in Karak is moderate because the relevant mean was moderate. That is because the total mean is 3.42. Behavioral self-efficacy is ranked first, whereas the cognitive self-efficacy is ranked second. The emotive self-efficacy is ranked third.

Educational supervisors show moderate self-efficacy level because there are factors that negatively affect their performance. That shall weaken their capacity to meet the work requirements efficiently. Thus, their perceptions about themselves shall be negatively affected.

The latter result is attributed to the educational supervisors' incapacity to utilize the available resources efficiently to meet the sought goal. It is also attributed to the fact that educational supervisors face difficulties and obstacles at work, such as: difficulties in organizing time, and difficulties in supervising and monitoring teachers. It is also attributed to the fact that educational supervisors lack the technical and administrative skills required for doing their tasks. Their lack of such skills is attributed to the scarcity of the training courses provided to them by the directorates of education.

Educational supervisors show moderate self-efficacy level because they adopt conventional methods for practicing educational supervision. It is also because they don't adjust their plans in accordance with the latest changes and developments in the field of education. It is also because educational supervisors in Karak face difficulties in adopting modern methods to perform their work tasks. It is also because they must comply with specific rigid regulations enforced by the directorates of education. It is also because there is strict control enforced on them. Such regulations and control hinder them from making good decisions. Thus, their performance shall be negatively affected leading to a low self-efficacy.

The latter result is consistent with the result concluded by Al-Fakhouri (2018). The latter researcher found that the respondents' self-efficacy level is moderate. However, the latter result is inconsistent with the result 
concluded by Al-Shawa (2016). The latter researcher found that the respondents' self-efficacy level is low.

\subsection{Discussion related to the third question:}

Q.3 Is there any statistically significant relationship -at the statistical significance level of a $\leq 0.05$ - between psychological stress and self-efficacy among educational supervisors in Karak?

It was found that there are statistically significant relationships between the psychological stress variables and the self-efficacy variables jointly and separately. Thus, there is a statistically significant relationship between psychological stress and self-efficacy among the educational supervisors in Karak. That is because the total value is .772.

It was found that psychological stress about financial issues has the strongest relationship with the selfefficacy dimensions jointly because the total value is 0.717 . It was found that psychological stress about relationships with colleagues has the weakest relationship with the self-efficacy dimensions jointly because the total value is 0.575 .

There is a statistically significant relationship between psychological stress and self-efficacy among educational supervisors in Karak. That is because those supervisors face many difficulties that hinder them from performing their work tasks efficiently. Thus, they shall experience much anxiety and fear which shall negatively affect their work performance. That shall negatively affect their self-efficacy.

The difficulties that hinder them from performing their work tasks efficiently shall make them experience psychological stress. That shall make them adopt the solutions that can be implemented quickly without taking into consideration the quality of these solutions. That shall negatively affect their work performance. Thus, their self-efficacy shall be negatively affected.

It should be noted that experiencing much psychological stress by educational supervisors shall lead to increasing the negative thoughts. That shall hinder them from thinking right about the way of doing their work tasks right. That shall reduce their self-efficacy level.

There is a statistically significant relationship between psychological stress and self-efficacy among respondents. That is because suffering from psychological stress shall lead to making wrong, inefficient or ineffective decisions, or decisions that don't suit the nature of the task. That's because psychological stress shall make educational supervisors feel distracted. Such distraction shall make them incapable of working efficiently. That shall lower their self-efficacy level.

It was found that psychological stress about financial issues has the strongest relationship with self-efficacy dimensions jointly. That's because financial issues are considered the most significant determinant of one's behavior and capacity to carrying out tasks efficiently. That's because facing financial difficulties shall hinder one from thinking right and working efficiently. To illustrate more, when one faces financial difficulties, he/she shall be searching constantly for methods that can provide him/her with additional income. That shall make one distracted when carrying out his/her work tasks. It shall negatively affect one's behaviors and make him/her inward-looking. That shall reduce one's knowledge and make him/her agitated at any situation he/she faces even it's an ordinary situation.

The latter result is consistent with the result concluded by Al-Fakhouri (2018) and Al-Shawa (2016). The latter researchers found that there is a statistically significant relationship between psychological stress and selfefficacy.

\subsection{Discussion related to the fourth question}

Q.4 Is there any statistically significant difference -at the statistical significance level of a $\leq 0.05$ - between the respondents' psychological stress levels which can be attributed to their (gender, educational qualification or experience)?

It was found that there isn't any statistically significant difference -at the statistical significance level of a $\leq 0.05$ - between the respondents' psychological stress levels that can be attributed to their (gender, educational qualification, or experience. That's because the respondents have similar capabilities and similar access to resources and information sources. Therefore, their work environments are similar. That shall make them share a similar psychological stress level. The latter result is attributed to the fact that respondents have similar financial status because they receive similar income and rewards which are considered low. Thus, respondents suffer from similar financial pressures and thus, they suffer from similar psychological stress level.

\subsection{Discussion related to the fifth question}

Q.5 Is there any statistically significant difference -at the statistical significance level of a $\leq 0.05$ - between the respondents' self-efficacy levels which can be attributed to their (gender, educational qualification, or experience)? It was found that there isn't any statistically significant difference -at the statistical significance level of a $\leq 0.05$ between the respondents' self-efficacy levels which can be attributed to their gender, educational qualification or experience. That's because self-efficacy isn't affected by demographic variables. In fact, it's affected by internal 
pressures, and external pressures. That's because there isn't any educational supervision task that requires having a specific experience or a specific educational qualification or being a female or male to perform it.

\section{Conclusion}

After analyzing the relevant data statistically, it was found that the overall psychological stress level of educational supervisors in Karak is moderate. It was found that that the overall self-efficacy level of educational supervisors in Karak is moderate because the relevant mean is moderate. It was found that there is a statistically significant relationship - at the statistical significance level is a $\leq 0.05$ - between psychological stress and self-efficacy among the educational supervisors in Karak. It was found that there isn't any statistically significant difference -at the statistical significance level of a $\leq 0.05$ - between the respondents' psychological stress levels that can be attributed to their (gender, educational qualification or experience). It was found that there isn't any statistically significant difference -at the statistical significance level of a $\leq 0.05$ - between the respondents' self-efficacy levels which can be attributed to their (gender, educational qualification, or experience. In the light of the aforementioned results, the Jordanian Ministry of Education must provide much attention to the reduction of the stress experienced by the ones working in the academic field.

\section{Recommendations}

In the light of the aforementioned results, the researchers suggested several recommendations. For instance, they recommend:

1- Raising the self-efficacy level of educational supervisors through holding training courses and workshops. Such courses and workshops must aim at promoting awareness about the significance of self-efficacy and its role in improving performance

2- Developing strategies by the Jordanian Ministry of Education for reducing the psychological stress levels of educational supervisors at Karak. That should be done because psychological stress can negatively affect the educational supervisors' work performance and capacity to do the required tasks

3- Holding symposiums for holding discussions about the methods that can be used for reducing the psychological stress level of educational supervisors. Through such symposiums, discussions must be held about the impact of psychological stress on educational supervisors' performance and self-efficacy

4- Making adjustments to the wages and reward system of educational supervisors. That should be done to reduce the financial pressures and psychological stress of educational supervisors. Such pressures and stress shall negatively affect the self-efficacy of educational supervisors.

\section{References Written in Arabic Language:}

Ibrahim, Elham (2016). The social and ideological identity statuses and their relationship with educational selfefficacy among the female students of the faculty of education at Shaqra University. The Journal of the faculty of education. 27 (105)

Abu Rahmeh, Mohammad Hasan (2012). Work-related stress and its relationship with job satisfaction among the educational supervisors at Gaza. MA Thesis. The Islamic University. Gaza.

Al-Jahureye, Fatema and Al-Thafry, Saeed (2018). The relationship between educational self-efficacy and psychological compatibility among the $7^{\text {th }}-12^{\text {th }}$ grade students in the Sultanate of Oman. The Journal of the Educational and Psychological studies. 12(1).

Al-Khaldy, Atta Allah Fu'ad (2008). Contemporary Issues in Counseling. Amman. Safa' publishing and distribution house

Al-Sa'dy, Mohammad (2012). The development of psychological identity and its relationship with self-efficacy expectations among students. Unpublished MA thesis. Amman Arab University

Al-Shdaifat, Basel (2014). The role of educational supervisors in developing the professional performance of social studies teachers in the schools affiliated with the directorates of the Northwestern Badiah in Mafraq. Damascus University Journal. 30(2)

Al-Shawa, Ahmad (2016). Self-efficacy and its relationship with psychological stress among the officers working at Palestinian security institutions. The Journal of Al-Najah University for Human Sciences Research. 30 (8).

Al- Ta'jan, Khalaf (2016). The contemporary competencies of educational supervision among the educational supervisors in Mafraq. The Teacher Journal. 217 (2).

Talafha, Feras, and Al-Hemran, Mohammad (2013). The Effect of Teaching Unit in Accordance with using of Cognitive Affective Interaction Model on the Perceived Self-Efficacy among 10th Grade Students. The Journal of Al-Najah University for Human Sciences Research. 27 (6).

Abdullah, Mohammad Qasem (2004). An introduction to psychological health. The second edition. Jordan. AlFeker Publication and Distribution House.

Alawneh, Shafiq; Al-Otoom, Adnan; Al-Jarah, Abed Al-Naser, and Abu Gazal, Mu'aweya (2006). Educational 
psychology: Theory and application. Amman. Al-Maseera Publication and Distribution House

Al-Alwan, Ahmad and Al-Mahasneh, Randah (2011). Self-efficacy in reading and its relationship with the extent of using reading strategies among a sample consisting from students enrolled the Hashemite University. The Jordanian Journal for Educational Sciences. 7(4).

Al-Ali, Majed; and Mohammad, Abed Al-Mutaleb (2016). Self-efficacy and its relationship with values and educational performance among secondary school students in Kuwait. The Educational Sciences Journal. $3(1)$

Al-Gareer, Ahmad and Abu Sa'd, Ahmad (2009). Dealing with psychological stress. Amman. Al-Shorouq Publication and Distribution House

Al-Fakhouri, Jumana (2018). Psychological stress and its relationship with the perceived self-efficacy among the teachers of blind students in the Northern cities. Unpublished MA thesis. Al-Khalil University. Palestine.

Welkenson, Greig (2013) Psychological stress. Translated by Zeinab Men'em. The first edition. Reyad. AlMu'alef Publication and Distribution House

Al-Yousif, Rami (2013). Social skills and their relationship with the perceived self-efficacy and educational achievement among a sample consisting from intermediate school students in Ha'el, Kingdom of Saudi Arabia in the light of some variables. The Journal of the Islamic University for Psychological and Educational Studies. 21(1).

\section{References Written in English Language:}

Ahsan, N., Abdullah, Z., Yong Gun Fie, D. \& Alam, S. (2009). A Study of Job Stress on Job Satisfaction among University Staff in Malaysia: Empirical Study, European Journal of Social Sciences, 8 (1), 121-131.

Arslan, N. (2017). Investigating the Relationship between Educational Stress and Emotional Self-Efficacy. Universal Journal of Educational Research. 5(10). 1736-1740

Artino, A. (2006). Self-efficacy beliefs: From educational theory to instructional practice. ERIC document reproduction service No. ED 499094).

Coffman, D. and Gilligan, T. (2002). Social support, stress, self-efficacy: effects on students' satisfaction. Journal of College Student Retention Research, theory and practice. 4(1), 53-66

Krohne, H.W. (2002). Stress and coping theories. Johannes Gutenberg. Universitat Mainz Germany.

Lawless H.T., and Heymann H. (1999) Descriptive Analysis. In: Sensory Evaluation of Food. Food science text series. Springer, Boston, MA

Palmer, D., Dixon, J. \& Archer, J. (2015). Changes in Science Teaching Self-efficacy among Primary Teacher Education Students, Australian Journal of Teacher Education, 40 (12).

Shoji, K., Cieslak, R., Smoktunowicz, E., Rogala, A., Benight, C. \& Luszczynska, A. (2015). Associations between job burnout and self-efficacy: A meta-analysis, An International Journal: Anxiety, Stress, \& Coping, 1-20.

Totolo, A. (2011). Adoption and use of computer technology among school supervisors in Botswana secondary schools. The International Information \& Library Review, 33 (2): 70-112.

Vaezi, S. \& Fallah, N. (2011). The Relationship between Self-efficacy and Stress among Iranian EFL Teachers, Journal of Language Teaching and Research, 2 (5).

Acknowledgement:

The researchers thank the respondents who participated in this study 